\title{
Comparison of the effects of DC031050, a class III antiarrhythmic agent, on hERG channel and three neuronal potassium channels
}

\author{
Ping $\mathrm{LI}^{1}$, Hai-feng SUN ${ }^{1}$, Ping-zheng ZHOU ${ }^{1}$, Chao-ying MA², Guo-yuan $\mathrm{HU}^{1}$, Hua-liang JIANG ${ }^{1}$, Min $\mathrm{LI}^{1}$, Hong $\mathrm{LIU}^{1,}$ *, Zhao-
} bing $\mathrm{GAO}^{1, *}$

${ }^{1}$ State Key Laboratory of Drug Research, Shanghai Institute of Materia Medica, Chinese Academy of Sciences, Shanghai 201203, China; ${ }^{2}$ Life Science and Engineering College of Southwest Jiaotong University, Chengdu 610031, China

Aim: This study was conducted to test the selectivity of DC031050 on cardiac and neuronal potassium channels.

Methods: Human ether-à-go-go related gene (hERG), KCNQ and Kv1.2 channels were expressed in CHO cells. The delayed rectifier potassium current $\left(I_{\kappa}\right)$ was recorded from dissociated hippocampal pyramidal neurons of neonatal rats. Whole-cell voltage patch clamp was used to record the voltage-activated potassium currents. Drug-containing solution was delivered using a RSC-100 Rapid Solution Changer.

Results: Both DC031050 and dofetilide potently inhibited $\mathrm{hERG}$ currents with $\mathrm{IC}_{50}$ values of $2.3 \pm 1.0$ and $17.9 \pm 1.2 \mathrm{nmol} / \mathrm{L}$, respectively. DC031050 inhibited the $I_{\mathrm{K}}$ current with an $\mathrm{IC}_{50}$ value of $2.7 \pm 1.5 \mu \mathrm{mol} / \mathrm{L}$, which was $>1000$ times the concentration required to inhibit hERG current. DC031050 at $3 \mu \mathrm{mol} / \mathrm{L}$ did not significantly affect the voltage-dependence of the steady activation, steady inactivation of $I_{K}$, or the rate of $I_{K}$ from inactivation. Intracellular application of DC031050 (5 $\left.\mu \mathrm{mol} / \mathrm{L}\right)$ was insufficient to inhibit $I_{\mathrm{K}}$. DC031050 up to $10 \mu \mathrm{mol} / \mathrm{L}$ had no effects on KCNQ2 and Kv1.2 channel currents.

Conclusion: DC031050 is a highly selective hERG potassium channel blocker with a substantial safety margin of activity over neuronal potassium channels, thus holds significant potential for therapeutic application as a class III antiarrhythmic agent.

Keywords: dofetilide; DC031050; class III antiarrhythmic agent; hERG; KCNQ; Kv1.2; delayed rectifier potassium current

Acta Pharmacologica Sinica (2012) 33: 728-736; doi: 10.1038/aps.2012.41; published online 21 May 2012

\section{Introduction}

Potassium channel blockers are categorised as class III antiarrhythmic agents due to their ability to prolong the duration of the cardiac action potential ${ }^{[1-4]}$. These drugs include ibutilide, somatilide, sotalol, azimilide, droneradone and amiodarone, which elicit their actions by blocking one or more cardiac potassium channels, such as $I_{\mathrm{Kr}}, I_{\mathrm{Ks}}$ and $I_{\mathrm{Kur}}$, among others. The class III antiarrhythmic drugs have been subject to extensive clinical investigation as safer and more effective alternatives to class I drugs, which exhibit recognised risks in selected populations ${ }^{[5-7]}$. However, numerous noncardiac side effects, such as nausea, drizzles and headaches, also frequently occur with the use of class III antiarrhythmic drugs. Some adverse effects outside of cardiac tissues are consistent with the observation that the class III agents have been found to act

\footnotetext{
* To whom correspondence should be addressed.

E-mail zb.gao@mail.shcnc.ac.cn (Zhao-bing GAO); hliu@mail.shcnc.ac.cn (Hong LIU).

Received 2012-02-10 Accepted 2012-03-28
}

on noncardiac ion channels. For example, tedisamil, a class III agent that is currently under evaluation in clinical trials, inhibits a calcium-dependent potassium (BK) channel of rat hippocampal CA1 neurons and guinea-pig portal vein smooth muscle cells. The inhibition of neuronal BK channels was thought to be related to nervous system toxicity associated with tedisamil ${ }^{[8,9]}$. E4031, a potent $I_{\mathrm{Kr}}$ blocker, exhibits inhibitory effects on all transient, sustained and inwardly rectifying potassium currents of rat taste cells ${ }^{[10]}$. Therefore, the assessment of the effects elicited by class III agents on noncardiac channels is important for evaluating the safety and clinical side effects of these drugs at an early stage of the drug discovery process.

Dofetilide is a relatively new class III antiarrhythmic drug that has been approved for the conversion of atrial fibrillation and flutter and the maintenance of normal sinus rhythm. It selectively blocks the rapid delayed rectifier potassium channel $\left(I_{\mathrm{Kr}}\right)$, but does not slow the delayed rectifier potassium channel $\left(I_{\mathrm{Ks}}\right) I_{\mathrm{K} 1}$, sodium channels or calcium channels ${ }^{[11,12]}$. To discover more effective class III antiarrhythmic agents, we 
have designed and synthesised a series of new methylsulfonamido phenylethylamine analogues based on the structure and pharmacophore of dofetilide ${ }^{[13,14]}$. Biological assays using guinea pig atria indicated that all of the analogues exert significant class III activities, including the prolongation of action potential duration and of effective refractory duration. Of all of the analogues, DC031050 (N-Benzyl-N-[2-(pmethanesulfonamindo phenoxy)ethyl]- $p$-methanesulfonamido Phenethylamine) was identified as one of the most effective compounds. At the very low concentration of $16 \mathrm{nmol} / \mathrm{L}$, DC031050 prolonged the effective refractory period for 10 ms. Furthermore, at a concentration of $10 \mu \mathrm{mol} / \mathrm{L}, \mathrm{DC} 031050$ improved the force of constriction significantly more $(24 \%)$ than dofetilide $(17 \%)^{[14]}$. A comparison of the chemical structures of DC031050 and dofetilide revealed that the substitution of the methyl group with a benzyl group in DC0310590 improves its biological activity (Figure 1) ${ }^{[14]}$, representing a modification strategy of dofetilide to obtain more effective class III agents. Prior to further modification, we sought to further understand the durability of these dofetilide-like class III analogues by assessing whether they acted on noncardiac channels. Thus, we evaluated DC031050 for its effects on three types of voltage-gated neuronal potassium channels: KCNQ2, Kv1.2 and a delayed rectifier in hippocampal neurons. Our results showed that only the delayed rectifier channel was inhibited by DC031050, but at 1000 times the concentration needed to block hERG.

\section{Materials and methods}

\section{Compound synthesis}

DC031050 was prepared according to previously reported procedures $^{[13,14]}$. The chemical structure of DC031050 is shown in Figure 1.

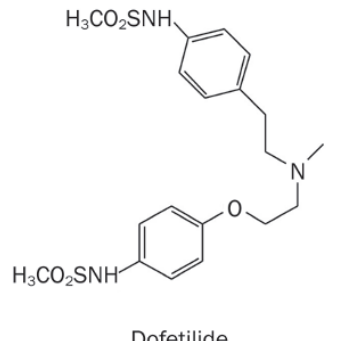

Dofetilide

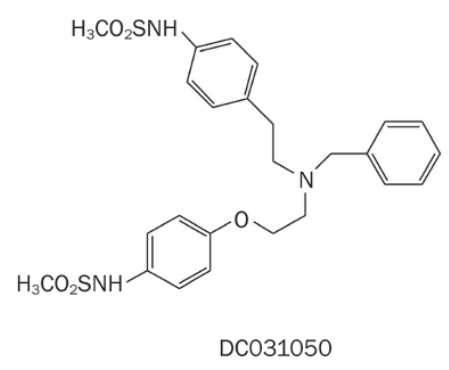

Figure 1. The chemical structure of compound DC031050 and dofetilide.

\section{Preparation of dissociated hippocampal pyramidal neurons}

Hippocampal neurons were dissociated from 5- to 9-day-old Sprague-Dawley rats as described previously. Briefly, minislices $(500 \mu \mathrm{m})$ of the hippocampal CA1 region were cut in an ice-cold, oxygenated dissociation solution containing the following components (in mmol/L): $\mathrm{Na}_{2} \mathrm{SO}_{4} 82, \mathrm{~K}_{2} \mathrm{SO}_{4} 30$, $\mathrm{MgCl}_{2}$ 5, HEPES 10 and glucose 10 (pH 7.3). The slices were incubated in a dissociation solution containing protease XXIII $\left(3 \mathrm{mg} / \mathrm{mL}\right.$ ) at $32^{\circ} \mathrm{C}$ for $8 \mathrm{~min}$. The solution was then replaced with dissociation solution containing trypsin inhibitor type II-S $(1 \mathrm{mg} / \mathrm{mL})$ and bovine serum albumin $(1 \mathrm{mg} / \mathrm{mL})$. The slices were allowed to cool to room temperature in an oxygenated solution. Before recording, the slices were triturated using a series of fire-polished Pasteur pipettes with progressively decreasing tip diameters. The dissociated neurons were placed into a recording dish and perfused with an external solution containing the following components (in $\mathrm{mmol} / \mathrm{L}$ ): $\mathrm{NaCl} 135, \mathrm{KCl} 5, \mathrm{MgCl}_{2}$ 2, HEPES 10, glucose 10 and tetrodotoxin 0.001 ( $\mathrm{pH} 7.3$ ).

\section{Cell culture and transfection}

Chinese hamster ovary (CHO) cells were grown in 50/50 DMEM/F12 (Cellgro, Manassas, VA) supplemented with 10\% fetal bovine serum (FBS) and $2 \mathrm{mmol} / \mathrm{L} \mathrm{L}$-glutamine (Gibco, Carlsbad, CA, USA). To overexpress the KCNQ and hERG channel proteins, the cells were split $24 \mathrm{~h}$ before transfection, plated into 60-mm dishes, and transfected with the appropriate plasmids using the Lipofectamine $2000^{\mathrm{TM}}$ reagent (Invitrogen, Carlsbad, CA, USA), according to the manufacturer's protocols. Twenty-four hours after transfection, the cells were split and re-plated onto coverslips coated with poly-L-lysine (Sigma-Aldrich, St Louis, MO, USA). A green fluorescent protein (GFP) expression plasmid (Amaxa, Gaithersburg, MD, USA) was cotransfected to allow for the identification of transfected cells by fluorescence microscopy.

\section{Whole-cell voltage-clamp recording of hippocampal neurons and cultured $\mathrm{CHO}$ cells}

The recordings were made at $21-23^{\circ} \mathrm{C}$ using an Axopatch 200B amplifier (Molecular Devices, Sunnyvale, CA, USA). Electrodes with a tip resistance of 3-5 M $\Omega$ were pulled from borosilicate glass pipettes (World Precision Instruments, Sarasota, Fl) and filled with a pipette solution containing the following components (in mmol/L): $\mathrm{KCl} 140, \mathrm{MgCl}_{2} 1, \mathrm{CaCl}_{2}$ 1, HEPES 10 and EGTA 10 (pH 7.3). Voltage protocols were provided by pClamp 9.2 software via a DigiData-1322A interface (Molecular Devices, Sunnyvale, CA, USA). Series resistance was compensated by $75 \%-85 \%$. For hippocampal neurons, the bath solution contained the following components (in mmol/L): $\mathrm{NaCl} 135, \mathrm{KCl} 5, \mathrm{MgCl}_{2}$ 2, HEPES 10, glucose 10 and tetrodotoxin $0.001(\mathrm{pH} 7.3)$. The cells were maintained at -50 $\mathrm{mV}$. The delayed rectifier current $\left(I_{\mathrm{K}}\right)$ in hippocampal neurons was elicited by a series of 400-ms depolarising steps from -70 $\mathrm{mV}$ to $+70 \mathrm{mV}$ in $10 \mathrm{mV}$ incremental steps following a 600-ms hyperpolarising pre-pulse to $-110 \mathrm{mV}$ and a 50 -ms interval at $-50 \mathrm{mV}$ immediately after the pre-pulse to inactivate the transient component of the current. The resulting signals were sampled at frequencies of $10-40 \mathrm{kHz}$ and filtered at $2-10 \mathrm{kHz}$. Linear leak and residual capacitance currents were subtracted on-line using a $\mathrm{P} / 4$ protocol. Unless otherwise stated, all $I_{\mathrm{K}}$ amplitudes were obtained at $300 \mathrm{~ms}$ after the initiation of the stimulating pulse. The effect of DC031050 was assessed after the neurons were exposed to the drug for $40 \mathrm{~s}$, and a minimum of 5-s interval was used between stimulations. 
For cultured $\mathrm{CHO}$ cells, the pipette solution contained the following components (in mmol/L): $\mathrm{KCl} 145, \mathrm{MgCl}_{2}$ 1, EGTA 5, HEPES 10, and Mg-ATP 5 ( $\mathrm{pH}=7.3$ with $\mathrm{KOH})$. The extracellular solution contained the following components (in mmol/L): $\mathrm{NaCl} 140, \mathrm{KCl} 3, \mathrm{CaCl}_{2}$ 2, $\mathrm{MgCl}_{2}$ 1.5, HEPES 10, and glucose 10 ( $\mathrm{pH}=7.4$ with $\mathrm{NaOH})$.

\section{Drug application}

DC031050 was dissolved in dimethylsulfoxide (DMSO) to prepare a $10 \mathrm{mmol} / \mathrm{L}$ stock solution, from which the appropriate volumes were added to the external or pipette solutions to produce the desired concentrations. DMSO (less than $0.1 \%$ in the final dilution) elicited no observable effect on the $\mathrm{K}^{+}$currents. For the electrophysiological recordings in neurons, the external solution containing DC031050 was delivered using a RSC-100 Rapid Solution Changer (BioLogic Co, France) that could change the external solution over the recorded neuron during a 10-ms period. For recordings in cultured CHO cells, a constant perfusion of extracellular solution was maintained using a BPS perfusion system (ALA scientific Instruments, Westburg, NY, USA). The DC031050 in the pipette solution was diffused into the neuron, and changes were recorded immediately after the rupture of the membrane patch. Unless otherwise stated, all chemicals were purchased from SigmaAldrich China Inc.

\section{Data analysis}

The concentration of DC031050 required to inhibit 50\% of the $\mathrm{K}^{+}$currents $\left(\mathrm{IC}_{50}\right)$ was determined by fitting normalised data to the equation $I / I_{0}=1 /\left\{1+\left([\mathrm{C}] / \mathrm{IC}_{50}\right)^{\mathrm{n}}\right\}$, where $I_{0}$ and $I$ are the current amplitudes measured in the absence and presence of the drug, respectively. [C] is the concentration of the drug in the external solution, and $\mathrm{n}$ is the Hill coefficient. For analysing the voltage-dependence of the steady-state activation or inactivation of the $\mathrm{K}^{+}$currents, normalised conductance or current was plotted against the membrane potential and fitted to the Boltzmann equations as follows: $Y=1 /\left\{1+\exp \left[\left(V-V_{1 / 2}\right) / k\right]\right\}$, where $Y$ is the normalised conductance or current, $V$ is the test potential, $V_{1 / 2}$ is the voltage at half-maximal activation or inactivation, and $k$ is the slope factor. The time course of recovery of the $\mathrm{K}^{+}$currents from inactivation was fitted with a mono-exponential function as follows: $I / I_{\max }=A^{*}\{1(\exp [(\Delta \mathrm{t} / \tau]\}$, where $I_{\max }$ is the maximal current amplitude, $I$ is the current after a recovery period of $\Delta t, \tau$ the time constant, and $A$ is the amplitude coefficient. Data are presented as mean \pm SEM. Statistical significance was assessed using Student's $t$-test, where $P<0.05$ was considered significant.

\section{Results}

\section{Inhibition of hERG channel by DC031050}

In our previous study, DC031050 exhibited typical class III agent activity in biological assays using guinea pig atria ${ }^{[14]}$. Given its structural similarity with dofetilide, we hypothesised that the biological activity of DC031050 was elicited by its inhibition of hERG channels. To test our hypothesis, hERG channel proteins were transiently expressed in $\mathrm{CHO}$ cells, and the resulting currents elicited by depolarisation step pulses followed by repolarisation to $-50 \mathrm{mV}$ were recorded. As shown in Figure 2A \& B, hERG currents were completely inhibited by

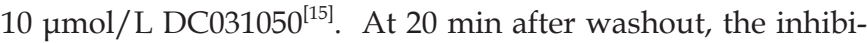
tory effects were not reversed. Analysis of the concentrationresponse relationships revealed an $\mathrm{IC}_{50}$ value of $2.3 \pm 1.0$ $\mathrm{nmol} / \mathrm{L}$. In contrast, the $\mathrm{IC}_{50}$ of dofetilide on hERG channels is $17.9 \pm 1.2 \mathrm{nmol} / \mathrm{L}$ (Figure 2D). The more potent inhibition of hERG channels by DC031050 compared to dofetilide is consistent with the potent biological activity of DC031050 observed in vivo ${ }^{[13,14]}$.

\section{Lack of effect of DC031050 on neuronal KCNQ2 and Kv1.2 channels expressed in $\mathrm{CHO}$ cells}

KCNQ channels, also called Kv7 channels, include five members. KCNQ2 and KCNQ3 form heterotetramers in the neurons and mediate the $\mathrm{M}$ current, a potassium current could be inhibited by activation of muscarinic receptor. Inhibition of the M current by a mutation of KCNQ2 or KCNQ3 can result in various pathologies including benign familial neonatal convulsion, a form of neuronal hyperexcitibility ${ }^{[16-18]}$. The importance of Kv1.2 channels in controlling neuronal excitability has been demonstrated by the observation that Kv1.x (Kv1.1 and Kv1.2) channel-inhibiting venom toxins induce seizures in rodents ${ }^{[19]}$. To evaluate the effect of DC0310050 on the neuronal potassium channels KCNQ2 and Kv1.2, two neuronal potassium channels that are important in the control of neuronal excitability, were expressed in CHO cells, and the voltagedependent channel activation was measured in the presence and absence of this drug. As shown in Figure 3, $10 \mu \mathrm{mol} / \mathrm{L}$ DC031050 did not significantly affect the current amplitude of either KCNQ2 or Kv1.2, suggesting that DC031050 might exhibit specificity for cardiac $I_{\mathrm{Kr}}$ channels.

\section{Concentration-dependent inhibition of $I_{\mathrm{K}}$ by DC031050 in rat hippocampal neurons}

The delayed rectifier outward potassium channel in neuronal tissues is a major potassium channel that is responsible for spike repolarisation, and it plays a similar role as $I_{\mathrm{Kr}}$ in the cardiac tissues ${ }^{[20]}$. The delayed rectifier potassium currents $\left(I_{\mathrm{K}}\right)$ were elicited in dissociated rat hippocampal pyramidal neurons by applying a 400-ms depolarising step to $+40 \mathrm{mV}$, following a $600-\mathrm{ms}$ hyperpolarising pre-pulse to $-110 \mathrm{mV}$ and a $50-\mathrm{ms}$ interval at $-50 \mathrm{mV}$ immediately after the prepulse. Figure $4 \mathrm{~A}$ shows representative superimposed traces before and after the application of increasing concentrations of DC031050 from $0.1 \mu \mathrm{mol} / \mathrm{L}$ to $10 \mu \mathrm{mol} / \mathrm{L}$. DC031050 exhibited clear inhibition of $I_{\mathrm{K}}$ in a concentration-dependent manner, and the inhibition was more pronounced at the later or steady state phase of the current development. Using 10 $\mu \mathrm{mol} / \mathrm{L}$ DC031050, the peak current was reduced by approximately 50\%, whereas the steady-state current at $300 \mathrm{~ms}$ was almost completely blocked. Unless stated otherwise, we used the amplitude of $I_{\mathrm{K}}$ at the steady state $(300 \mathrm{~ms})$ for all subsequent analyses. The concentration-response curve revealed an $\mathrm{IC}_{50}$ value of $2.7 \pm 1.5 \mu \mathrm{mol} / \mathrm{L}$, and a Hill coefficient of $1.1 \pm 0.2$ 
A
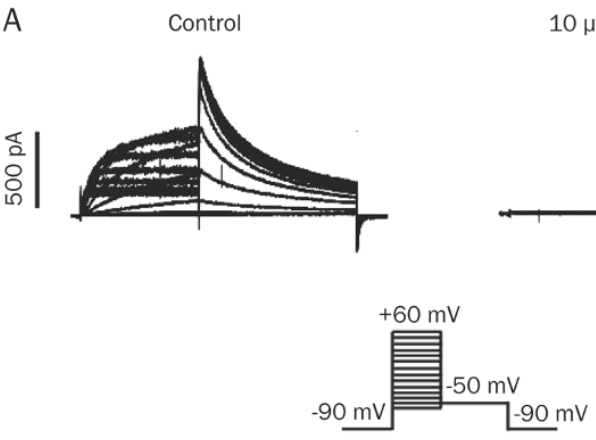

C

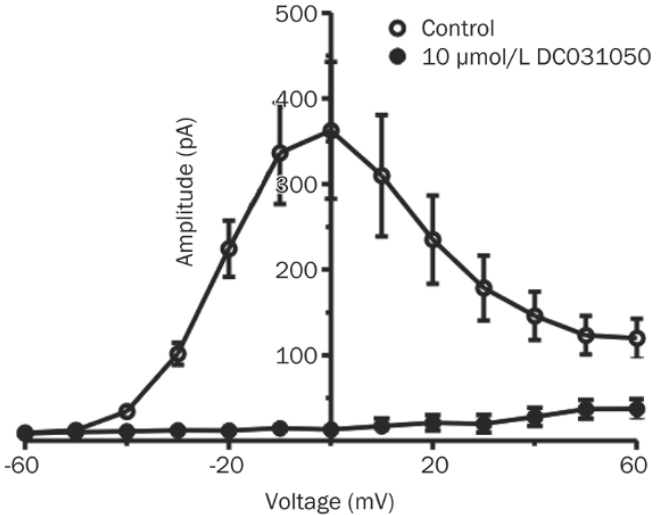

B

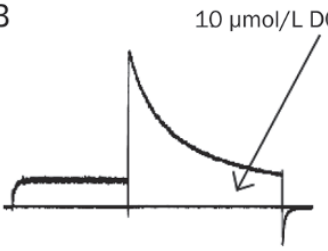

$-90 \mathrm{mv} \underbrace{+50 \mathrm{mV}}_{\frac{\mathrm{s}}{-50 \mathrm{mV}}}$

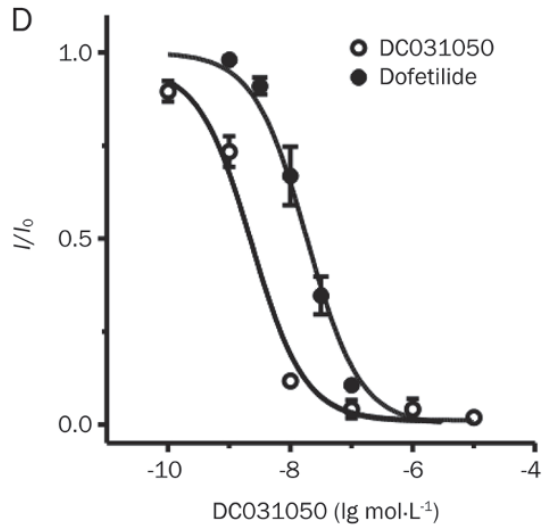

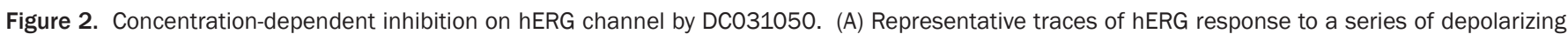

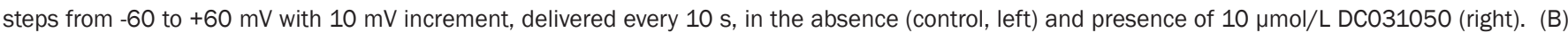

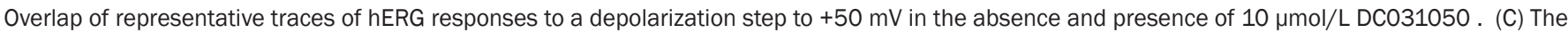

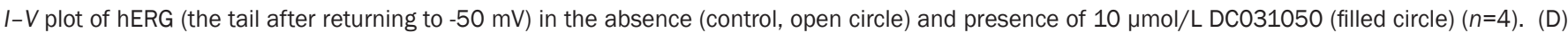
Dose dependence of hERG channel inhibition on DC031050 and dofetilide $(n=6)$.

for the DC031050-induced inhibition of $I_{\mathrm{K}}$ (Figure 4B, $n=6$ ). The inhibitory effect was reversible, as the current returned to near-control levels upon washout for $40 \mathrm{~s}$ (Figure 4C).

In addition to inducing a concentration-dependent reduction of $I_{\mathrm{K}}$ amplitude, DC031050 markedly accelerated the decay of the current, which appeared as a more pronounced inhibition of the steady-state current than of the peak current (Figure $4 \mathrm{~A} \& 4 \mathrm{C}$ ). To quantify this effect, the decay time course of $I_{\mathrm{K}}$ was fitted with a mono-exponential function. As shown in Figure 4D, the acceleration of the current decay was also concentration-dependent. The decay time constant $(\tau)$ decreased gradually $(208.4,163.3,155.5,112.7,75.8$, and 54.4 $\mathrm{ms})$ with increasing concentrations of DC031050 (0, 0.1, 0.3, 1 , 3 , and $10 \mu \mathrm{mol} / \mathrm{L}$, respectively). Similar results were observed in 4 individual neurons. Plotting the time constant against the concentration revealed an $\mathrm{IC}_{50}$ value of $1.2 \pm 0.7 \mu \mathrm{mol} / \mathrm{L}(\mathrm{n}=4)$, which is essentially identical to the $\mathrm{IC}_{50}$ value obtained using steady-state current amplitude.

\section{Effect of DC031050 on the kinetic properties of neuronal $I_{\mathrm{K}}$}

The inhibition of neuronal $I_{\mathrm{K}}$ by DC031050 was voltage-independent. Figures $5 \mathrm{~A} \& 5 \mathrm{~B}$ show the representative traces and current-voltage $(I / V)$ relationships of $I_{\mathrm{K}}$ in the absence and presence of $3 \mu \mathrm{mol} / \mathrm{L}$ DC031050. The current was activated at $50 \mathrm{mV}$, and the control $I / V$ relationship was almost linear at depolarising potentials. After treatment with $3 \mu \mathrm{mol} / \mathrm{L}$ DC031050, the $I / V$ curve of $I_{\mathrm{K}}$ exhibited an apparent proportional downward shift, where the $I / I_{0}$ values $\left(I_{0}\right.$ represents the original current without the drug) were nearly constant at all depolarising step pulses (Figure $5 \mathrm{~B}$ ). The $I / I_{0}$ values at 0 $\mathrm{mV}, 20 \mathrm{mV}, 40 \mathrm{mV}$, and $60 \mathrm{mV}$ were $50.8 \% \pm 4.9 \%, 46.9 \% \pm 4.4 \%$, $49.2 \% \pm 4.2 \%$, and $49.0 \% \pm 2.4 \%$, respectively $(n=6, P>0.05)$.

In addition, treatment with $3 \mu \mathrm{mol} / \mathrm{L}$ DC031050 did not significantly change the voltage-dependence of the activation of steady-state currents (Figure 5C), the voltage-dependence of inactivation (Figure 5D), or the rate of channel recovery from inactivation (Figure 5E). In the presence of $3 \mu \mathrm{mol} / \mathrm{L}$ DC031050, the voltage for half-maximal activation was $-8.4 \pm 1.6$ $\mathrm{mV}$ compared to $-6.9 \pm 1.0 \mathrm{mV}$ for the control $(n=6, P>0.05)$; the voltage for half-maximal inactivation was $-78.7 \pm 1.1 \mathrm{mV}$ compared to $-81.9 \pm 1.3 \mathrm{mV}$ for the control treatment $(n=6, P>0.05)$; and the time constant of recovery from inactivation was $261.4 \pm 39.1 \mathrm{~ms}$ compared to $223.7 \pm 16.4 \mathrm{~ms}$ for the control treatment $(n=6, P>0.05)$. 

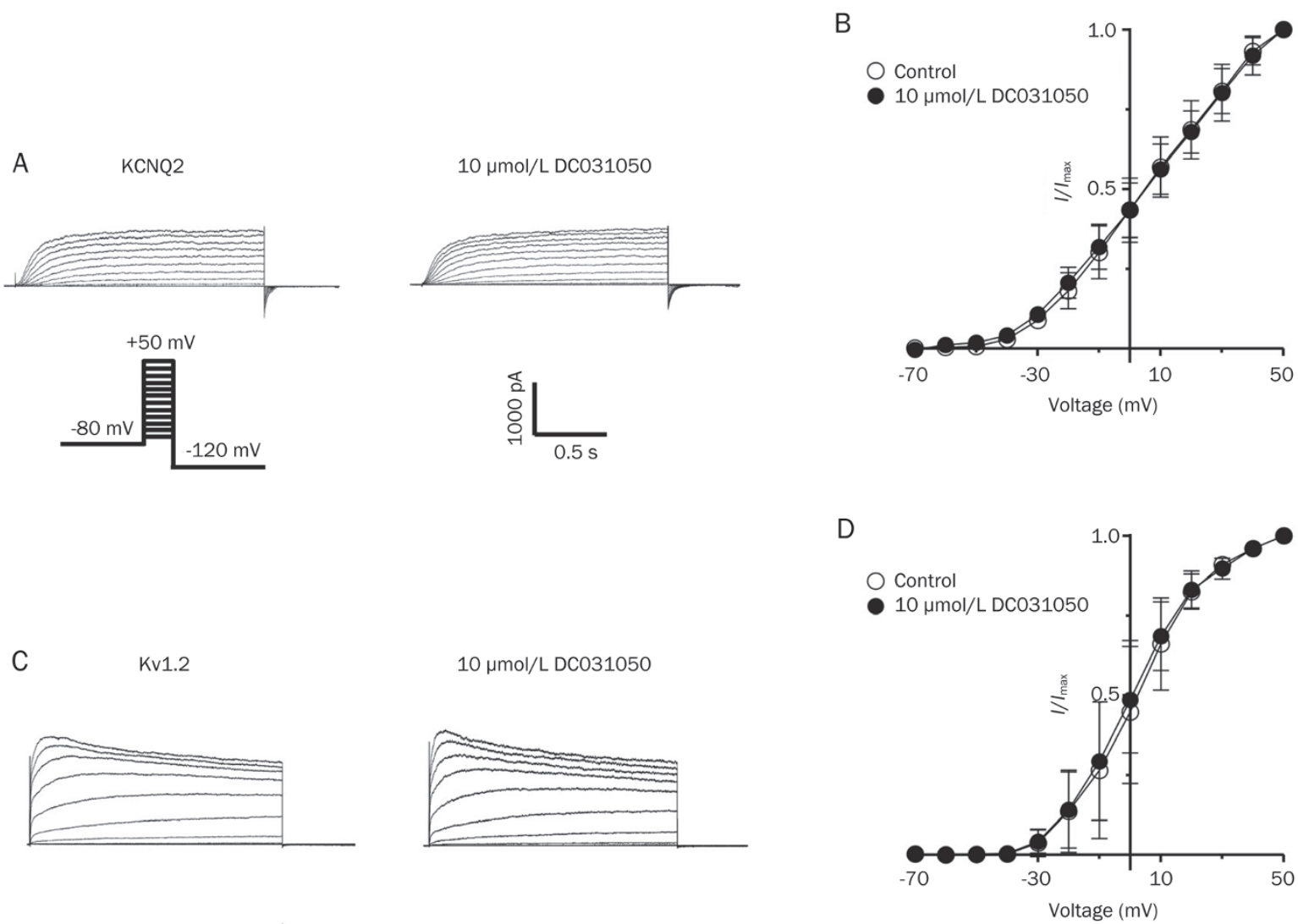

Figure 3. Effects of DC031050 on KCNQ2 and Kv1.2 channels expressed in $\mathrm{CHO}$ cells. (A) Representative KCNQ2 traces elicited by a series of depolarizing steps from $-70 \mathrm{mV}$ to $+50 \mathrm{mV}$ with $10 \mathrm{mV}$ increment, delivered every $3 \mathrm{~s}$, in the absence (left) and presence of $10 \mu \mathrm{mol} / \mathrm{L} \mathrm{DC0} 31050$ (right). (B) Summary data showing the relative activity of KCNQ2 in the presence of $10 \mu \mathrm{mol} / \mathrm{L}$ DC031050 normalized to that of control ( $n=7$ ). (C) Representative Kv1.2 traces elicited by a series of depolarizing steps from $-90 \mathrm{mV}$ to $+50 \mathrm{mV}$ with $10 \mathrm{mV}$ increment, delivered every $3.5 \mathrm{~s}$, in the absence (left) and presence of $10 \mu \mathrm{mol} / \mathrm{L}$ DC031050 (right). (D) Summary of normalized data for $10 \mu \mathrm{mol} / \mathrm{L}$ DC031050 effect on Kv1.2 channel ( $n=4)$.

DC031050 acts at the extracellular face of the neuronal $I_{\mathrm{K}}$ channel

To determine the inhibitory mechanism of DC031050, we took two different approaches. First, we assessed the effects of the intracellular application of the compound. In control neurons dialysed with the normal pipette solution (see Methods), $I_{\mathrm{K}}$ exhibited a slight decrease (less than 10\%) within 10 min after membrane rupture. We applied $5 \mu \mathrm{mol} / \mathrm{L}$ DC031050 for the intracellular application because the external application of the same concentration inhibited the $\mathrm{K}^{+}$currents by approximately $70 \%-90 \%$ (Figure 4A). However, as shown in Figures 6A \& $6 \mathrm{~B}$, the time course of $I_{\mathrm{K}}$ in neurons dialysed with the pipette solution containing $5 \mu \mathrm{mol} / \mathrm{L}$ DC031050 exhibited results that were almost identical to that of the control-treated group ( $n=5$ for each), indicating that the intracellular application of 5 $\mu \mathrm{mol} / \mathrm{L}$ DC031050 was insufficient to inhibit $I_{\mathrm{K}}$.

The above findings support the idea that the DC031050 might act at extracellular site(s). The binding site of TEA, a well-known potassium channel blocker, has been found to localise to the outer mouth of the KcsA channel ${ }^{[21,22]}$. To determine if the action sites of DC031050 includes the outer mouth of the delayed rectifier $\mathrm{K}^{+}$channel, the inhibitory effects of DC031050 were tested in the presence or absence of 15 $\mathrm{mmol} / \mathrm{L}$ TEA in the external solution. Interestingly, co-treatment with $15 \mathrm{mmol} / \mathrm{L}$ TEA significantly reduced the inhibitory effect of DC031050. For example, treatment with $3 \mu \mathrm{mol} /$ L DC031050 resulted in an $I / I_{0}$ value of $75.2 \% \pm 9.2 \%$ in the presence of $15 \mathrm{mmol} / \mathrm{L}$ TEA compared to $47.8 \% \pm 8.4 \%$ induced by the control treatment $(n=5, P<0.05)$. In the presence of 15 $\mathrm{mmol} / \mathrm{L}$ TEA, the concentration response curve of DC031050 was significantly right-shifted compared to the control treatment, with the $\mathrm{IC}_{50}$ increasing to $7.4 \pm 1.2 \mu \mathrm{mol} / \mathrm{L}$ from $2.7 \pm 1.5$ $\mu \mathrm{mol} / \mathrm{L}$ in the control $(n=5, P<0.05)$.

\section{Discussion}

Class III antiarrhythmic agents and their inhibitory effects on noncardiac potassium channels

On the basis of their dominant electrophysiological activities, antiarrhythmic drugs are categorised into four broad classes: I, II, III, and IV. Class I agents are sodium channels blockers that inhibit the impulse conduction and contractility in myocardial tissues; class II agents are beta-blockers; class III agents delay the repolarisation of cardiac myocytes; and class IV agents are calcium channel blockers ${ }^{[23]}$. Atrial fibrillation $(\mathrm{AF})$ represents 
A

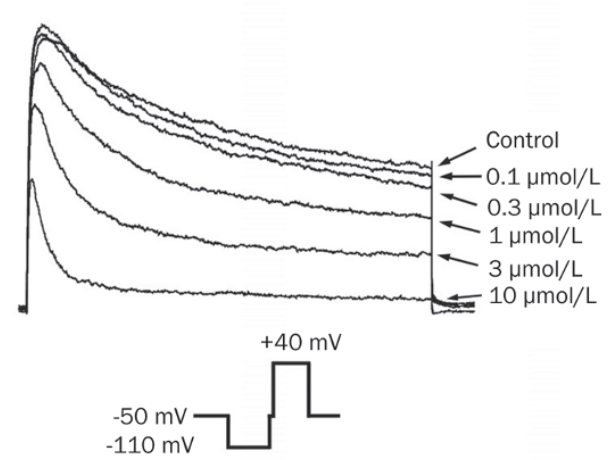

C

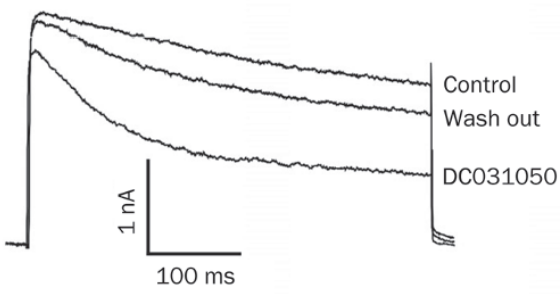

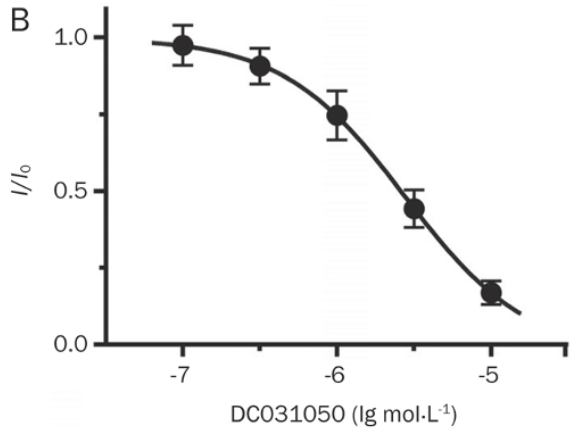

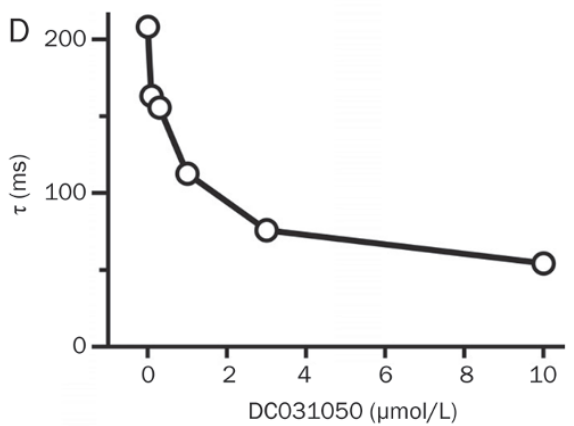

Figure 4. Concentration-dependent inhibition on $I_{K}$ by DC031050. (A) Representative traces of delayed rectifier $\mathrm{K}^{+}$currents $\left(I_{K}\right)$ in the presence of increasing concentrations of $\operatorname{DC0} 1050(0,0.1,0.3,1,3$, and $10 \mu \mathrm{mol} / \mathrm{L})$ recorded from one hippocampal neuron. Currents were elicited with steps to $+40 \mathrm{mV}$ and measured at $300 \mathrm{~ms}$ latency of the test pulses. (B) Concentration-inhibition curve of DC031050 on $I_{\mathrm{K}}$. Each symbol represents the mean \pm SEM. $n=6$. (C) The superimposed traces before, during and $40 \mathrm{~s}$ after washout of $3 \mu \mathrm{mol} / \mathrm{L}$ DC031050. (D) DC031050 accelerated decay of $I_{K}$. The plot was the decay time constant of the current traces in control (A) and against the concentrations of DC031050. Similar results were obtained from 4 neurons.

a major type of arrhythmia for which antiarrhythmic drugs have a predominant clinical application. Since the 1990s, class IA agents, such as quinidine, have not been the first choice for the treatment of atrial fibrillation because of increased mortal${ }^{i t y}{ }^{[24]}$. Such agents have since been displaced by an increasing interest in class III agents that primarily prolong cardiac action potential repolarisation ${ }^{[4,25]}$. However, the application of class III agents for the conversion and prevention of atrial fibrillation in high-risk patients has not yielded the successful results expected. For example, long-term treatment with the class III agent $D$-sotalol is associated with an increased risk of mortality compared with treatment with placebo ${ }^{[1,26]}$. In addition to the severe risk to cardiac tissues, the tolerance of certain class III agents has yielded disappointing results. For example, the class III agent amiodarone is associated with a $41 \%$ discontinuation rate that is attributed to its side effects and toxicity in liver, thyroid and pulmonary tissues ${ }^{[27]}$.

Dofetilide (Tikosyn ${ }^{\mathrm{TM}}$ ) is a relatively recent class III antiarrhythmic drug that has been approved for the conversion of AF and the maintenance of normal sinus rhythm. Dofetilide has a higher safety profile than most other class III agents. In 10 randomised trials for treatment of supraventricular arrhythmias, the hazard ratio for death of dofetilide was 1.1 (95\% confidence interval 0.3-4.3), indicating no evidence of a side effect for dofetilide on mortality rates ${ }^{[28,29]}$. Two separate
Danish Investigations of Arrhythmia and Mortality on Dofetilide (DIAMOND) studies performed in high-risk patients also demonstrated the safety of dofetilide ${ }^{[29]}$. Why dofetilide exhibited a low mortality ratio, whereas other class III agents (eg, $D$-sotalol) increased mortality, remains elusive. Because of the high safety profile of dofetilide, we designed and synthesised a series of structural analogues with the goal of developing novel class III antiarrhythmic agents. The biological activities of these analogues were assessed in biological assays using guinea pig atrial tissues. DC031050 was identified as one of the most potent compounds that demonstrated typical class III antiarrhythmic agent activity ${ }^{[13,14]}$.

However, similar to other class III antiarrhythmic agents, dofetilide exhibits general noncardiac side effects, including headache, dizziness, rash and some nervous system effects, such as paralysis, migraine and syncope ${ }^{[30,31]}$. Although there is no direct evidence linking these side effects to the dysfunction of noncardiac ion channels, the functional disorders of noncardiac ion channels are known to cause these syndromes. For example, mutations of brain-specific $\mathrm{P} / \mathrm{Q}$ type calcium channels were linked to familial hemiplegic migraines ${ }^{[32]}$, whereas the functional down-regulation of Kir2.6, an inwardly rectifying potassium channel, was linked to thyrotoxic hypokalemic periodic paralysis ${ }^{[33]}$. Consistent with its adverse effects in the nervous system, a low concentration $(100 \mu \mathrm{mol} / \mathrm{L})$ of 
A
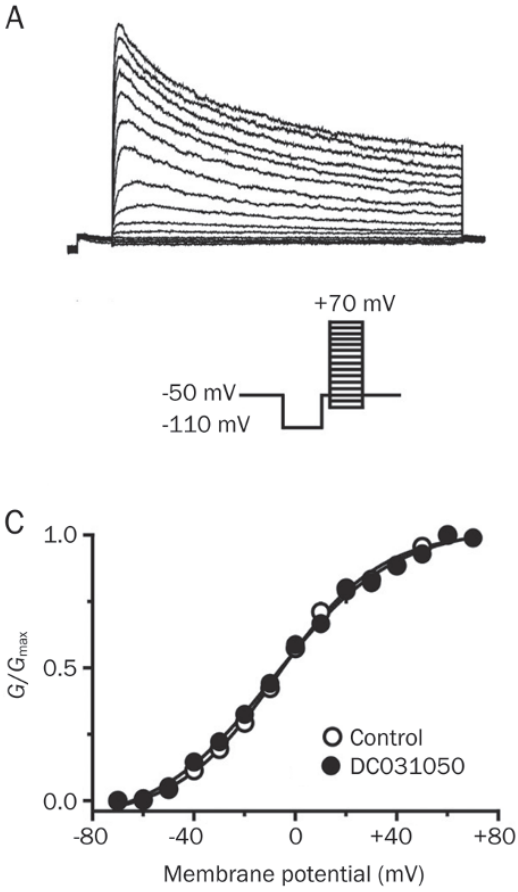
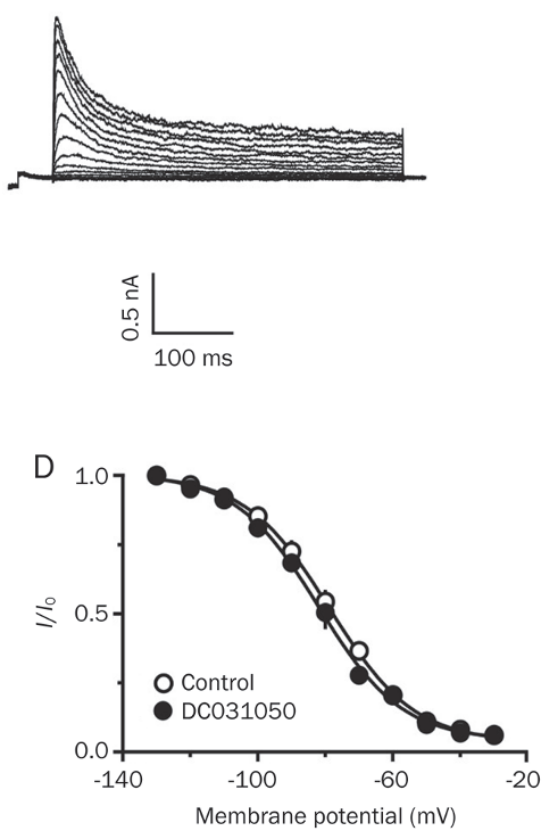

B
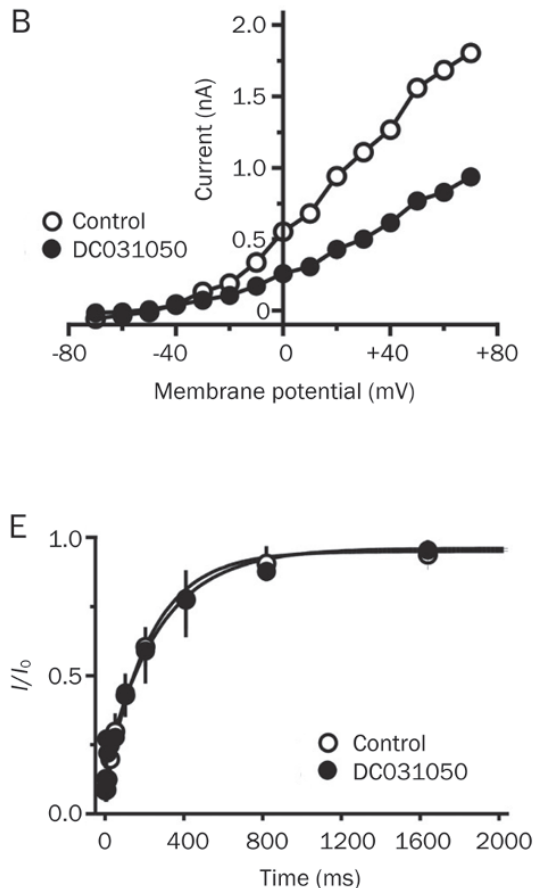

Figure 5. Effects of DC031050 on kinetic properties of $I_{\mathrm{K}}$. (A) Responses of a representative neuron to a series of depolarizing steps from -70 to +70 $\mathrm{mV}$ with $10 \mathrm{mV}$ increment, delivered every $10 \mathrm{~s}$, in the absence and (control, left) and presence of $3 \mu \mathrm{mol} / \mathrm{L}$ DC031050 (right). (B) Current-Voltage $(\mathrm{I} / \mathrm{V})$ curves of $I_{\mathrm{K}}$ before and during application of $3 \mu \mathrm{mol} / \mathrm{L}$ DC031050. (C, D, and E) show the voltage-dependence of activation (C), inactivation (D) and the time course of recovery from inactivation (E), in the absence and presence of $3 \mu \mathrm{mol} / \mathrm{L}$ DC031050. Three different protocols were used. The protocol to study voltage-dependent activation is shown in inset. For studying the steady-state inactivation, neurons were held at $0 \mathrm{mV}$, and currents were elicited with a series of $600-\mathrm{ms}$ prepulses at different hyperpolarizing potentials followed by a $400-\mathrm{ms}$ step to $+40 \mathrm{mV}$, then back to $0 \mathrm{mV}$, delivered every $10 \mathrm{~s}$. For studying the time course of recovery from inactivation, neurons were held at $0 \mathrm{mV}$, and currents were elicited on return from hyperpolarizing prepulse of varying durations at $-110 \mathrm{mV}$ to $+40 \mathrm{mV}$, delivered every $10 \mathrm{~s}$. Current of peak were used for plotting.

dofetilide acted on ion channels in hippocampal neurons (eg, the voltage-independent block of a calcium-dependent potassium channel $(\mathrm{BK}))^{[34]}$. Notably, the plasma concentration of dofetilide exceeds $100 \mathrm{nmol} / \mathrm{L}$ when administered at $1 \mathrm{mg}$ twice daily continuously for $24 \mathrm{~h}^{[35]}$.

DC031050 is a dofetilide analogue that more potently blocks hERG channels, with an excellent safety margin on neuronal potassium channels

In the current study, we confirmed that DC031050 is a potent and complete blocker of hERG, with an $\mathrm{IC}_{50}$ value of 2.3 $\mathrm{nmol} / \mathrm{L}$, which is significantly less than the $\mathrm{IC}_{50}$ of dofetilide on hERG channels $(17.9 \mathrm{nmol} / \mathrm{L})$. hERG channels are cardiac potassium channels that are known to significantly influence the duration of cardiac action potentials. Thus, the electrophysiological data on heterologously expressed hERG channels is consistent with the results obtained from biological assays using guinea pig atria ${ }^{[13,14]}$. Surveying a number of noncardiac potassium channels revealed that DC031050 (at 10 $\mu \mathrm{mol} / \mathrm{L}$ concentration) elicited negligible effects on KCNQ2 and Kv1.2 channels that were expressed in $\mathrm{CHO}$ cells, but was sufficient to block $I_{\mathrm{K}}$ in rat hippocampal neurons. The $\mathrm{IC}_{50}$ of DC031050 on $I_{K}$ was $2.7 \mu \mathrm{mol} / \mathrm{L}$, which is more than 1000fold higher than that on hERG. Thus, DC031050 should pro- vide a broad concentration range for the selective therapeutic blockade of hERG channels without affecting other noncardiac potassium channels. The high selectivity of DC031050 on hERG channels strongly supports its potential for therapeutic application as a class III antiarrhythmic agent. The inhibitory effects on neuronal $I_{\mathrm{K}}$ at the micromolar concentrations argue for further early drug discovery stage evaluation of the effects of this compound on noncardiac channels to obtain safer class III antiarrythymia drugs. This is particularly important given that, in addition to $I_{\mathrm{K}}, \mathrm{KCNQ} 2$ and $\mathrm{Kv} 1.2$, there are many other types of potassium channels that are expressed in neuronal tissues. To fully discern the safety of DC031050, the effects of the drug on other noncardiac potassium channels should be further studied.

Inhibition of neuronal delayed rectifier potassium channel by DC031050

The inhibition of DC031050 on the delayed rectified potassium channels in rat hippocampal neurons is dose dependent and exhibits the following principal properties. (1) DC031050 markedly accelerated the decay of $I_{\mathrm{K}}$ in a concentration-dependent manner, which is consistent with more potent inhibition of the steady state current than of the peak current. These data suggest that DC031050 might be an open-channel blocker, 
A

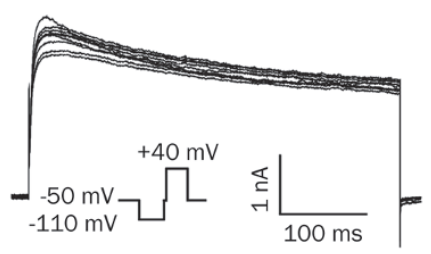

D

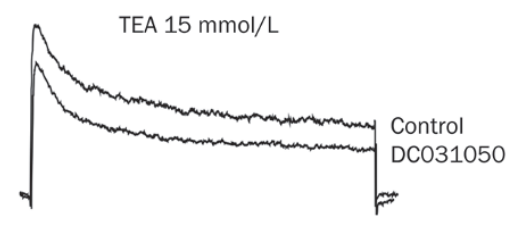

B
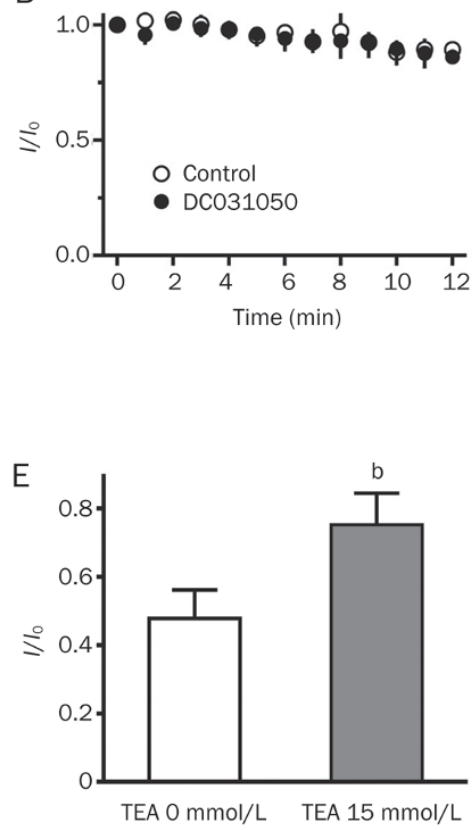

C

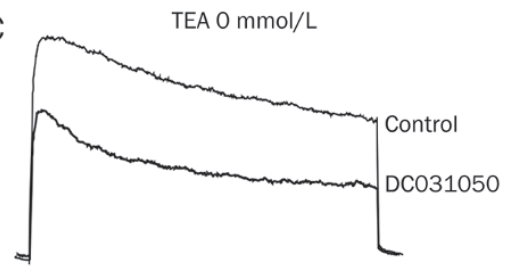

F

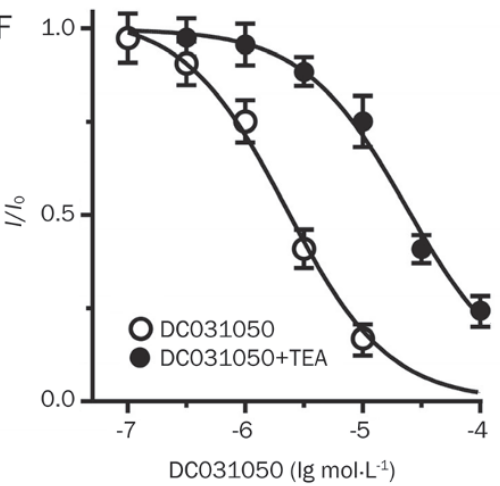

Figure 6. DC031050 acts on extracellular side of $I_{\mathrm{K}}$ channel. (A) A family of representative traces of $I_{\mathrm{K}}$ elicited by steps to $+40 \mathrm{mV}$ every $1 \mathrm{~min}$ during intracellular dialysis of $5 \mu \mathrm{mol} / \mathrm{L}$ DC031050. (B) The relative current $\left(I / I_{0}\right)$ against recording time shows the lack of effect of intracellular application of DC031050. Zero in the abscissa indicates the time when patch membrane was ruptured. (C, D) Superimposed traces show DC031050 inhibition in the presence and absence of $15 \mathrm{mmol} / \mathrm{L} \mathrm{TEA}$ in the external solution, respectively. (E) Normalized current in the presence of $5 \mu \mathrm{mol} / \mathrm{L}$ DC031050 as compared to control without or with $15 \mathrm{mmol} / \mathrm{L}$ TEA in the external solution. Each column is mean $\pm \mathrm{SEM}$. $(n=5, P<0.05)$. (F) Concentration response curve of inhibition by DC031050 in the presence and absence of $15 \mathrm{mmol} / \mathrm{L}$ TEA in the external solution. Currents were normalized to that in the absence of DC031050 in the same experiment $(n=6)$.

indicating that opening of the channel is a prerequisite to blocking. Alternatively, DC031050 might accelerate the inactivation of $I_{K}$. (2) DC031050 does not alter the kinetic properties of $I_{\mathrm{K}}$. DC031050 elicited no significant effects on either the voltage-dependence of inactivation or the time course of recovery from inactivation, which precludes the notion that this drug might act through acceleration of channel inactivation.

Two experiments supported the notion that DC031050 might act at the extracellular face of $I_{\mathrm{K}}$ channels. In contrast to the marked inhibition of $I_{\mathrm{K}}$ elicited by the external perfusion of

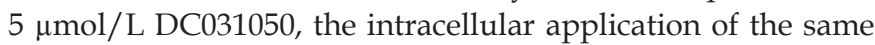
concentration of this drug elicited a negligible effect. Furthermore, the inhibition of DC031050 was diminished by co-treatment with $15 \mathrm{mmol} / \mathrm{L}$ TEA, which is known to block potassium channels from the extracellular face. This indicates that when a TEA molecule occupies the external TEA binding site, a steric hindrance effect might prevent DC031050 from interacting with the channel. Combined with the observed acceleration of decay and the lack of effects on kinetics, DC031050 appears to be an open channel blocker, which acts at an external binding site(s) on the outer mouth of the neuronal delayed rectifier potassium channel.

In summary, we have identified DC031050, an analogue of dofetilide, as a highly selective hERG potassium channel blocker with an excellent safety margin over neuronal potas- sium channels. DC031050 exhibits therapeutic potential as a class III antiarrhythmic agent. Our study strongly supports the evaluation of effects elicited by class III agents on noncardiac channels at early stages of the drug discovery process.

\section{Acknowledgements}

We gratefully acknowledge Michael Xi ZHU for his comments on this manuscript and the financial support from the National Natural Science Foundation of China (81072579, 20872153, and 81025017).

\section{Author contribution}

Zhao-bing GAO, Hong LIU, and Hua-liang JIANG designed research; Ping LI, Hai-feng SUN and Ping-zheng ZHOU performed research; all authors analyzed data; Ping LI, Hai-feng SUN, Hong LIU, Zhao-bing GAO, and Guo-yuan HU wrote the paper.

\section{References}

1 Lazzara R. From first class to third class: recent upheaval in antiarrhythmic therapy - lessons from clinical trials. Am J Cardiol 1996; 78: 28-33.

2 Phillips GB, Morgan TK Jr, Nickisch K, Lind JM, Gomez RP, Wohl RA, et al. Synthesis and cardiac electrophysiological activity of arylsubstituted derivatives of the class III antiarrhythmic agent sematilide. 
Potential class I/III agents. J Med Chem 1990; 33: 627-33.

3 Selnick HG, Liverton NJ, Baldwin JJ, Butcher JW, Claremon DA, Elliott $\mathrm{JM}$, et al. Class III antiarrhythmic activity in vivo by selective blockade of the slowly activating cardiac delayed rectifier potassium current $I_{\mathrm{Ks}}$ by (R)-2-(2,4-trifluoromethyl)- $N$-[2-oxo-5-phenyl-1-(2,2,2-trifluoroethyl)2,3-dihydro-1H-benzo[e][1,4]diazepin-3-yl]acetamide. J Med Chem 1997; 40: 3865-8.

4 Sahar DI, Reiffel JA, Bigger JT Jr, Squatrito A, Kidwell GA. Efficacy, safety, and tolerance of $d$-sotalol in patients with refractory supraventricular tachyarrhythmias. Am Heart J 1989; 117: 562-8.

5 Vaughan Williams EM. A classification of antiarrhythmic actions reassessed after a decade of new drugs. J Clin Pharmacol 1984; 24 : 129-47.

6 Colastsky TJ. Ahtiarrhythmic drugs: where are we going? Technical review. Pharm News 1995; 2: 17-23.

7 MacNeil DJ. The side effect profile of class III antiarrhythmic drugs: focus on d,I-sotalol. Am J Cardiol 1997; 80: 90G-98G.

8 Pfrunder D, Kreye VA. Tedisamil blocks single large-conductance $\mathrm{Ca}^{2+}$ activated $\mathrm{K}^{+}$channels in membrane patches from smooth muscle cells of the guinea-pig portal vein. Pflugers Arch 1991; 418: 308-12.

9 Church J, McLarnon JG. Tedisamil blocks BK-type $\mathrm{Ca}^{2+}$-dependent $\mathrm{K}^{+}$channels and modulates action potentials in rat hippocampal neurons. Neurosci Lett 2002; 319: 79-82.

10 Sun XD, Herness MS. Inhibition of potassium currents by the antiarrhythmic drug E4031 in rat taste receptor cells. Neurosci Lett 1996; 204: 149-52.

11 Lenz TL, Hilleman DE. Dofetilide, a new class III antiarrhythmic agent. Pharmacotherapy 2000; 20: 776-86.

12 Lenz TL, Hilleman DE. Dofetilide: a new antiarrhythmic agent approved for conversion and/or maintenance of atrial fibrillation/ atrial flutter. Drugs Today (Barc) 2000; 36: 759-71.

13 Liu H, Ji M, Jiang H, Liu L, Hua W, Chen K, et al. Computer-aided design, synthesis and biological assay of $p$-methylsulfonamido phenylethylamine analogues. Bioorg Med Chem Lett 2000; 10: 2153-7.

14 Liu H, Ji M, Luo X, Shen J, Huang X, Hua W, et al. New p-methylsulfonamido phenylethylamine analogues as class III antiarrhythmic agents: design, synthesis, biological assay, and 3D-QSAR analysis. J Med Chem 2002; 45: 2953-69.

15 Kiehn J, Lacerda AE, Wible B, Brown AM. Molecular physiology and pharmacology of HERG. Single-channel currents and block by dofetilide. Circulation 1996; 94: 2572-9.

16 Xiong Q, Gao Z, Wang W, Li M. Activation of Kv7 (KCNQ) voltage-gated potassium channels by synthetic compounds. Trends Pharmacol Sci 2008; 29: 99-107.

17 Shapiro MS, Roche JP, Kaftan EJ, Cruzblanca H, Mackie K, Hille B. Reconstitution of muscarinic modulation of the KCNQ2/KCNQ3 $\mathrm{K}^{+}$ channels that underlie the neuronal M current. J Neurosci 2000; 20: 1710-21.

18 Wang HS, Pan Z, Shi W, Brown BS, Wymore RS, Cohen IS, et al. KCNQ2 and KCNQ3 potassium channel subunits: molecular correlates of the M-channel. Science 1998; 282: 1890-3.

19 Bagetta G, Nistico G, Dolly JO. Production of seizures and brain damage in rats by alpha-dendrotoxin, a selective $\mathrm{K}^{+}$channel blocker.
Neurosci Lett 1992; 139: 34-40.

20 Storm JF. Action potential repolarization and a fast after-hyperpolarization in rat hippocampal pyramidal cells. J Physiol 1987; 385: 733-59.

21 Guidoni L, Carloni P. Tetraethylammonium binding to the outer mouth of the KcsA potassium channel: implications for ion permeation. J Recept Signal Transduct Res 2002; 22: 315-31.

22 Heginbotham L, Mackinnon R. The aromatic binding site for tetraethylammonium ion on potassium channels. Neuron 1992; 8: 48391.

23 Singh BN, Hauswirth O. Comparative mechanisms of action of antiarrhythmic drugs. Am Heart J 1974; 87: 367-82.

24 Effect of the antiarrhythmic agent moricizine on survival after myocardial infarction. The Cardiac Arrhythmia Suppression Trial II Investigators. N Engl J Med 1992; 327: 227-33.

25 Singh BN. The coming of age of the class III antiarrhythmic principle: retrospective and future trends. Am J Cardiol 1996; 78: 17-27.

26 Julian DG, Prescott RJ, Jackson FS, Szekely P. Controlled trial of sotalol for one year after myocardial infarction. Lancet 1982; 1 : 1142-7.

27 Grimm W, Maisch B. Sudden cardiac death in dilated cardiomyopathy - therapeutic options. Herz 2002; 27: 750-9.

28 Frost L, Mortensen PE, Tingleff J, Platou ES, Christiansen EH, Christiansen N. Efficacy and safety of dofetilide, a new class III antiarrhythmic agent, in acute termination of atrial fibrillation or flutter after coronary artery bypass surgery. Dofetilide Post-CABG Study Group. Int J Cardiol 1997; 58: 135-40.

29 Pedersen OD, Bagger H, Keller N, Marchant B, Køber L, Torp-Pedersen $C$, et al. Efficacy of dofetilide in the treatment of atrial fibrillationflutter in patients with reduced left ventricular function: a Danish investigations of arrhythmia and mortality on dofetilide (diamond) substudy. Circulation 2001; 104: 292-6.

30 Rasmussen HS, Allen MJ, Blackburn KJ, Butrous GS, Dalrymple HW. Dofetilide, a novel class III antiarrhythmic agent. J Cardiovasc Pharmacol 1992; 20 Suppl 2: S96-105.

31 Falk RH, Pollak A, Singh SN, Friedrich T. Intravenous dofetilide, a class III antiarrhythmic agent, for the termination of sustained atrial fibrillation or flutter. Intravenous Dofetilide Investigators. J Am Coll Cardiol 1997; 29: 385-90.

32 Terwindt GM, Ophoff RA, Haan J, Vergouwe MN, van Eijk R, Frants $\mathrm{RR}$, et al. Variable clinical expression of mutations in the P/Q-type calcium channel gene in familial hemiplegic migraine. Dutch Migraine Genetics Research Group. Neurology 1998; 50: 1105-10.

33 Ryan DP, da Silva MR, Soong TW, Fontaine B, Donaldson MR, Kung AW, et al. Mutations in potassium channel Kir2.6 cause susceptibility to thyrotoxic hypokalemic periodic paralysis. Cell 2010; 140: 88-98.

34 McLarnon JG, Wang XP. Actions of cardiac drugs on a calciumdependent potassium channel in hippocampal neurons. Mol Pharmacol 1991; 39: 540-6.

35 Walker DK, Alabaster CT, Congrave GS, Hargreaves MB, Hyland R, Jones BC, et al. Significance of metabolism in the disposition and action of the antidysrhythmic drug, dofetilide. In vitro studies and correlation with in vivo data. Drug Metab Dispos 1996; 24: 447-55. 